Case report

\title{
OVERLAPPING PRIMARY AND SECONDARY SYPHILIS IN HUMAN IMMUNODEFICIENCY VIRUS (HIV) PATIENT
}

\author{
Nurul Laili Nahlia ${ }^{1 *}$, Lita Setyowatie ${ }^{2}$ \\ 1,2) Department of Dermatology and Venereology, Faculty of Medicine, Universitas Brawijaya / dr. Saiful Anwar Regional \\ General Hospital Malang, Indonesia
}

\begin{tabular}{ll} 
A R T I C L E I N F O \\
\hline Submitted & : February 2020 \\
Accepted & : May 2020 \\
Published & : July 2020 \\
\hline
\end{tabular}

Keywords:

primary syphilis, secondary syphilis, HIV

\section{*Correspondence:}

nurul.laili.nahlia@gmail.com

\begin{abstract}
Coinfection between syphilis and Human Immunodeficiency Virus (HIV) could have varied clinical manifestations. Overlapping of syphilis stages is accounted for $25 \%$ of cases, attributable to the defect of the cellular and humoral immune response. We reported 55 years old man who was sexually active since 25 years ago via genito-genital, genito-anal, genito-oral routes, had multiple sexual partners both male and female, seldom used condom, and always being the insertive. Dermatological examination revealed alopecia nonscarring, a painless solitary ulcer on the collum penis, also multiple erythematous macules, patches, and plaques all over the body. Spirochaeta $s p$. was found from the base of the ulcer with a darkfield microscope. Histopathology examination revealed secondary syphilis lesion. Venereal Disease Research Laboratory (VDRL) 1:16, Treponema Pallidum Haemagglutination test (TPHA) reactive, HIV Determine rapid test reactive, and CD4 (Cluster of Differentiation 4) T-cell count 111 cells/ $\mu \mathrm{L}$. He was treated with a single dose of benzathine penicillin $G$ 2,4 million units intramuscular and antiretroviral drugs. On sixth month evaluation, VDRL was non-reactive, and CD4 T-cell count 325 cells $/ \mu \mathrm{L}$. This case shows that overlapping clinical manifestations of primary and secondary syphilis on HIV patients could occur with a good general condition. Immediate treatment of antibiotics for syphilis and antiretroviral could improve the clinical and serological conditions.
\end{abstract}




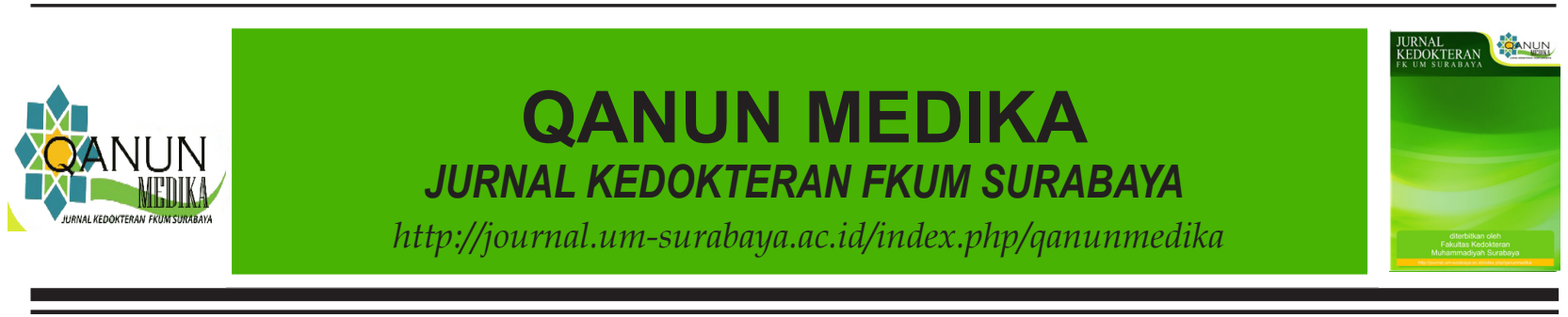

\section{INTRODUCTION}

Syphilis is a systemic disease caused by Treponema pallidum infection. This bacterial infection has a close relationship with Human Immunodeficiency Virus (HIV); both could be transmitted through sexual intercourse, often having coinfection, and could affect one another. World Health Organization (WHO) estimates there are 12 million new cases of syphilis every year, and $90 \%$ are in developing nations (Karp et al. 2009). While the prevalence of people with HIV in Indonesia was $0,4 \%$ of all adult population in 2018 , that is as much as $640.000(550.000-$ 750.000) cases (UNAIDS 2020).

Syphilis could increase the risk of HIV transmission about 3-5 times higher (Pisani et al. 2004). Primary syphilis lesions on genitalia could be the HIV portal of entry and facilitate the transmission. People with HIV/AIDS are eight times more often to have positive syphilis serologic tests. Beside, syphilis could also increase the infection capacity of HIV. Syphilis seroconversion on HIV patients closely related to multiple sexual partners, drugs, struck up on the internet, and serosorting habit. The course of syphilis has a staging of clinical manifestation (primary stage, secondary stage, and tertiary stage) and asymptomatic or latent stage (Lukehart 2008). The course of infection on HIV, generally more severe, even more often, are asymptomatically. One of four syphilis and HIV patient having a primary and secondary lesion appear concurrently (Karp et al. 2009). HIV infection could give rise to varied clinical manifestations because of cellular immunity defect (Carlson et al. 2011). This paper will be reported in one case of bisexuals with overlapping primary and secondary syphilis and HIV.

\section{CASE REPORT}

A 55-years-old man came to dermatology and venereology outpatient clinic dr. Saiful Anwar Regional General Hospital (RSSA) complaining red rashes all over his body for three weeks before consulted. No complaint of itchy, pain, burn, nor numbness sensation on the rashes. His hair was starting to fell off since the appearance of outbreaks. He also complains of a wound on his genitalia for two days before consulted, which was painless, odorless, not even producing any secret. There was a history of mild fever, weakness, lethargy, decreased arousal and appetite, and decreased body weight for seven months before consulted. He was diagnosed with HIV by internist from private hospital two days before asked to a dermatologist and given antiretroviral therapy.

Currently, the patient works as an entrepreneur and has a boarding house business. He was never married. He had a sexual history since 25 years ago with male boyfriends, multiple partners, through a genital-anal and a genital-oral sexual course, he instead on "top" position, and never used condoms. Complaints on partners were denied. He also had sexual intercourse with female sex workers (FSW), through genitalgenital or oral-genital sexual courses, rarely used condoms, complaints on sexual partners unknown. The last history of sexual intercourse was seven months ago with male boyfriend, through a genital-anal or a genital-oral sexual course, the patient rather on "top" position, did not use condoms. Complaints on the partner are denied.

His vital sign was normal, without any enlargement of lymph nodes. Dermatological examination revealed alopecia on the frontoparietal region (Figure 1A), a hair-pull test was negative. No abnormalities were found in the oral cavity. Scattered on the scalp, face, body, arms, legs, and also palms and soles, there 
were multiple erythematous macules, patches, and plaques with indistinct boundaries, varied in shape and size with an average diameter of $<2 \mathrm{~cm}$, non-confluent, and diascopy non-branch able (Figure 1B). On the penile shaft, there were solitary ulcers, round shape, with a diameter of about $1 \mathrm{~cm}$, distinct border, not curled, the base is clean, no pain with touch or pressure is obtained (Figure 1C).

We revealed Spirochaeta $s p$. from the base of the ulcer (Figure 2A). A punch biopsy was taken from the erythematous plaque then processed and stained with Hematoxylin and Eosin ( $\mathrm{H} \& \mathrm{E}$ ), appearing thickened epidermis, marked acanthosis, dyskeratosis, and vacuolar degeneration. In the dermis, there appears to be a group of lymphocyte cells and round nucleated plasma cells with eccentric nuclei forming perivascular and periadnexal granulomas, dilated blood vessels and endothelial swelling like a cobblestone (figure 2B \& 2C). Laboratory tests are shown in Table 1.
The patient was diagnosed with overlapping primary and secondary syphilis and HIV and treated with Benzathine Penicillin G 2.4 million units single-dose intramuscular and antiretroviral therapy of nevirapine $200 \mathrm{mg}$ twice a day and a combination of lamivudine $150 \mathrm{mg}$ and zidovudine $300 \mathrm{mg}$ in the capsules twice a day. There were JarischHerxheimer reactions and were controlled with the administration of Paracetamol $1500 \mathrm{mg}$ dividing dose. We educated patients regarding the disease, to loyal to one partner, and to use condoms when having sexual intercourse.

Reddish rashes all over his body gradually became hyperpigmented a few days after therapy. The genital ulcer was healed 2 days after therapy. At the first and third month evaluation, there were no complaints from the patient. Dermatological examination revealed alopecia on the frontoparietal scalp with a negative hair-pull test (Figure 1D). No abnormalities in the genitalia nor throughout the body (Figure 1E). Laboratory tests are shown in Table 1. 


\section{QANUN MEDIKA Vol 4 No 2 JULY 2020}
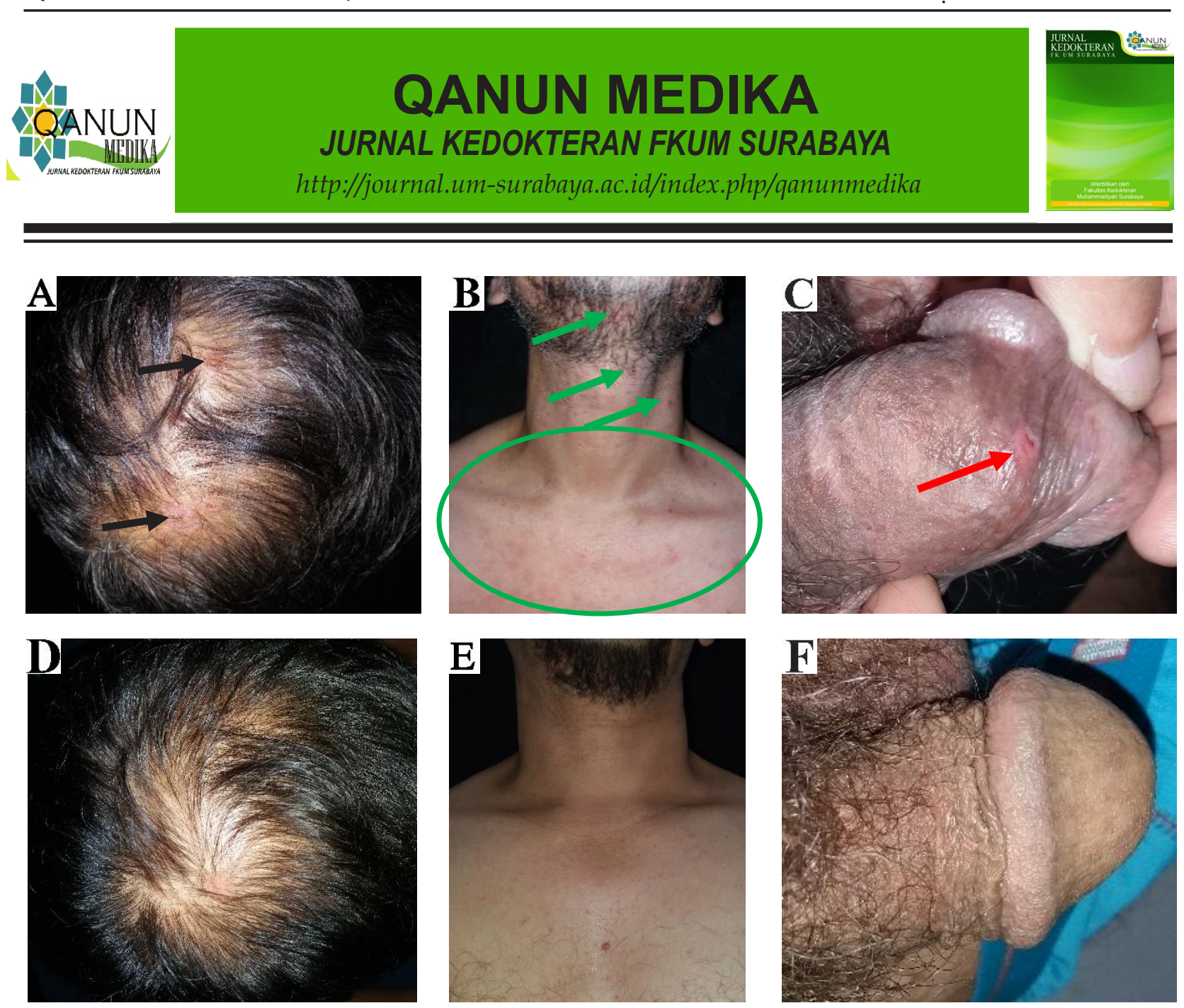

Figure 1. Dermatological examination at first visite $(\mathrm{A}-\mathrm{C})$ and $6^{\text {th }}$-month evaluation $(\mathrm{D}-\mathrm{F})$. A. On frontoparietal, there were alopecia non-scarring with multiple erythematous papules (black arrows). B. on the neck, there were multiple discrete erythematous macules and papules, representing the same lesion all over the body (green marking). C. On the collum penis, there were shallow ulcers, a distinct border, and a clean base (red arrow). D. Alopecia without any other rash. E-F. No rash all over body and genitalia.
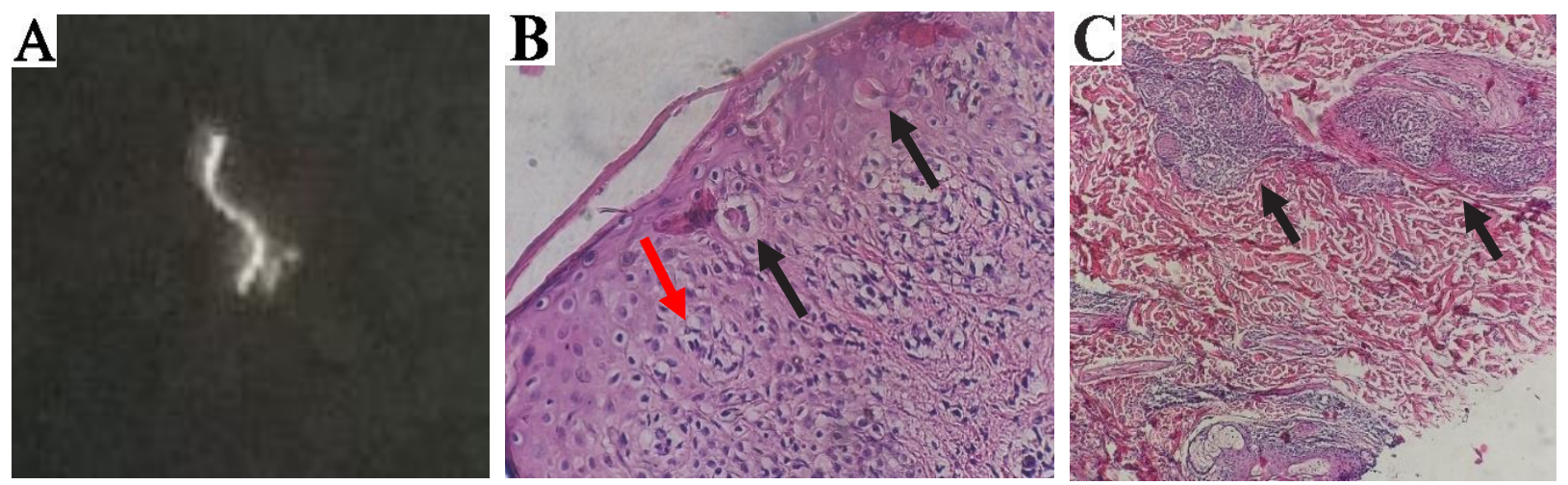

Figure 2. Laboratory examination. A. A Spirochaeta sp. (darkfield microscope, x200). B-C. Histopathological examination, H\&E. B. The thickened epidermis, marked acanthosis, dyskeratosis (black arrows), and vacuolar degeneration (red arrow) (x400). C. A group of lymphocyte cells and round nucleated plasma cells with eccentric nuclei forming perivascular and periadnexal granulomas (black arrows), dilated blood vessels and endothelial swelling like a cobblestone $(\mathrm{x} 400)$. 
Table 1. Laboratory examination

\begin{tabular}{cclc}
\hline Month & VDRL & TPHA & CD4 T-cell count (cells/ $\boldsymbol{\mu L})$ \\
\hline 0 & $1: 16$ & Reactive & 111 \\
1 & $1: 4$ & Reactive & - \\
3 & $1: 4$ & Reactive & 314 \\
6 & Non-reactive & Reactive & 325 \\
\hline
\end{tabular}

VDRL, Veneral Disease Research Laboratory. TPHA, Treponema Pallidum Haemagglutination test.

\section{DISCUSSION}

Syphilis epidemiology had been raised for years since the beginning of this century, and HIV likewise. This is consistent with the changing of sexually risky behavior (Pisani et al. 2004; Solomon and Mayer 2015). Even though the data about syphilis and HIV incidence in Asian countries is limited and most reporting syphilis prevalence regardless HIV status, some study report the prevalence of syphilis and HIV are higher in the key population such as men who have sex with men (MSM), transgender, and male/female sex worker (MSW/FSW) (Ahn et al. 2016; Daili et al. 2013).

Syphilis and HIV infections have a synergistic negative effect (strengthening each other). Both have effects on cellular and humoral immunity. Biologically, primary syphilis could increase transmission of HIV; epithelial and mucosal surfaces damage becomes a portal of entry for the virus to reach the systemic circulation. Genital mucosal damage caused by the bacteria could facilitate the transmission of HIV virion through the recruitment of inflammatory cells or increase the number of receptors expressed by each cell Dendritic cells that express the CD4 receptor and CCR5 (C-C chemokine receptor type 5) are the main targets of HIV1. Macrophage-tropic (M-tropic) strains, the most infectious HIV strains frequently transmitted sexually, use CCR5 as a co-receptor for viruses. Meanwhile, HIV-1 T-tropic cells use the chemokine receptor, CXCR4 (C-X-C chemokine receptor type 4), and replicate in T-cells. Treponema pallidum lipoprotein can increase HIV-1 replication by inducing the expression of the HIV-1 gene in human monocytes via NF- $\kappa \beta$-dependent mechanism. Humoral response to HIV infection is secondary activation of polyclonal B-cells caused by CD8 T-cells suppression, this results in an increase in immunoglobulin levels, and the decrease in serological syphilis titers will be longer than expected. The second response is the activation of suppressed B-cells so that there is a decrease in response to mitogens or antigens, causing false negatives on serological tests (Carlson et al. 2011).

In the presence of HIV coinfection, the clinical manifestations that determine the stages of syphilis can vary, and each stage can overlap (Table 2). These variations might be due to a defect in humoral and cellular immunity. Qualitative changes in the immune system in HIV patients can cause acceleration of the appearance of secondary lesions, more atypical features, more extensive and slow healing of primary lesions. Syphilis and HIV patients more often manifest as secondary syphilis compared to patients without HIV, and chancre coexistence can occur. Also, they are more likely to develop into neurosyphilis, which appears clinically (Carlson et al. 2011; Hutchinson et al. 1994). Simultaneous clinical manifestations of primary and secondary syphilis can occur in $25 \%$ of HIV coinfected 


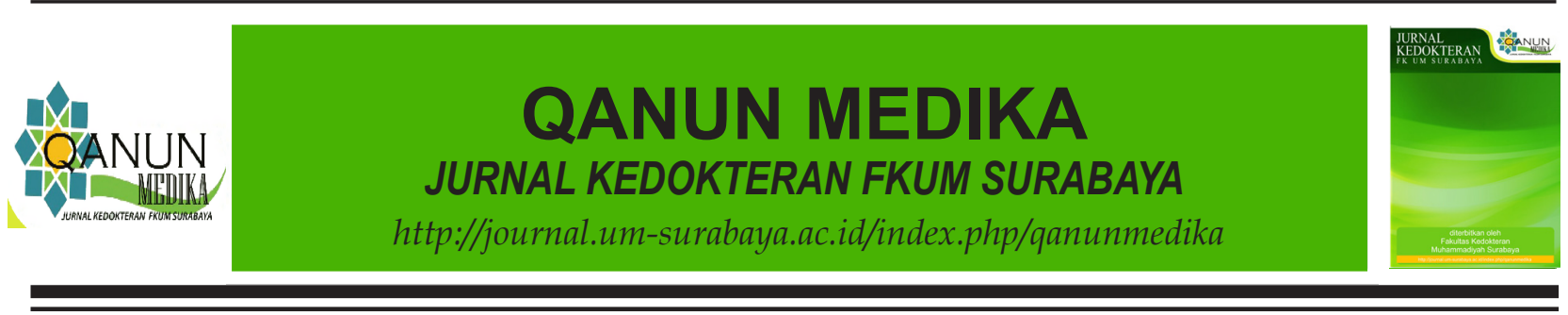

patients (Szetela and Gasiorowski 2016). The tendency of this disseminated syphilis is usually increased with the number of CD4 T-cells of less than 200 cells $/ \mu$ L (Jackson and Price 2013).

Alopecia in the frontoparietal region of the patient that occurred in the last seven months, indicates hair loss. A simple method for evaluating hair loss is a hair pull test. Three hairs are removed from the entire head area with a hair bulb so that patients are suspected of having non-scarring alopecia (Jackson and Price 2013). Alopecia non-inflammatory and non-scarring could be caused by syphilis infection, though it is rare. This type of alopecia should be differentiated with alopecia areata, trichotillomania, traction alopecia, and alopecia neoplastic, which can all be ruled out by biopsy (de Sousa 2013).

Most guidelines and experts agree that serological tests for syphilis can be interpreted the same in patients with or without HIV infection. If the titer is deemed inappropriate, a serological test and direct method (dark field microscope and/or painting of Warthin-Starry silver or fluorescent antibody on biopsy tissue) can be performed (Frieden et al. 2015; Rowawi, Djayakusumah, and Achdiat 2018). Besides, patients with syphilis and HIV who have a higher risk of neurosyphilis are still unclear. Guidelines from the European Union and the USA recommend a pre-therapy cerebrospinal fluid examination in advanced latent syphilis or unknown duration of HIV if the CD4 T-cell count is less than 350 cells $/ \mathrm{mm}^{3}$ and the RPR (Rapid plasma reagin) titer exceeds 1:32 (Frieden et al. 2015).

The therapeutic recommendation for early and advanced syphilis is benzathine penicillin $\mathrm{G}$; it has a long half-life, appropriate with the 30-hours-division of T. pallidum, and not toxic. The regimen is the same as in patients without HIV because no syphilis therapy regimen was more effective for preventing neurosyphilis in HIV patients. The recommended therapeutic regimen is benzathine penicillin $\mathrm{G} 2.4$ million unit single-dose intramuscular for primary and secondary syphilis with HIV. The use of antiretroviral therapy, according to HIV guidelines, is recommended in these patients. The addition of benzathine penicillin $\mathrm{G}$ doses or other antibiotics, such as amoxicillin, in primary and secondary syphilis did not show significant differences (Frieden et al. 2015).

Table 2. Atypical features of syphilis in the HIV-seropositive patients

- Higher rate of symptomless primary syphilis.

- Primary syphilis with multiple or deeper chancres.

- Higher rate of secondary disease.

- Overlap of primary and secondary stage features of syphilis.

- Increased rate of early neurologic and ophthalmic involvement.

- More rapid progression to tertiary manifestation.

- Report of false-negative serology in both primary and, less commonly, in secondary syphilis.

- Reduced efficacy of standard therapy for early syphilis.

- Relapse is more frequent.

- Jarisch-Hersheimer reaction is more frequent.

- Normalization of CSF values after treatment: delayed.

- Prozone phenomenon more frequent.

HIV: Human Immunodeficiency Virus

Source: Pialoux et al. 2008 
Treatment with a high dose of penicillin can cause side effects such as the JarischHerxheimer reaction and anaphylactic shock. The Jarisch-Herxheimer reaction is the reaction of acute fever followed by headache, myalgia, fever, and other symptoms that occur during the first 24 hours after syphilis therapy. This reaction is not a hypersensitivity reaction, but rather the presence of cytokines triggered by the dead T. pallidum lipoprotein, so penicillin therapy does not need to be stopped, and antipyretics can be used to treat symptoms (Rowawi, Djayakusumah, and Achdiat 2018).

VDRL titers should drop four times fold at three months, eight times fold at six months, and be negative in 1 year for primary syphilis and two years for secondary syphilis. The VDRL titer of our patient became non-reactive after six months. Smith in 1950 shows that $21 \%$ of syphilis and HIV patients treated with benzathine penicillin $G$ for primary and secondary syphilis were getting relapse after 18 months while 3 out of 4 patients with secondary syphilis and HIV did not recover. It should be noted that the serological response to therapy are more unpredictable in patients with HIV but does not indicate a worse clinical response (Carlson et al. 2011). Clinical and serological follow-up of treatment was carried out at $3^{\text {rd }}$, $6^{\text {th }}, 9^{\text {th }}, 12^{\text {th, }}$ and $24^{\text {th }}$ months after therapy. If at any time, clinical symptoms reappear or persist, or nontreponemal titers remain or increase, cerebrospinal fluid examination and repeat therapy should be carried out (Rowawi, Djayakusumah, and Achdiat 2018).

\section{CONCLUSION}

We reported one case with a diagnosis of overlapping primary syphilis and secondary syphilis and HIV in 55-year-old male patients with a good general condition. Diagnosis is based on history, physical examination, dark field microscope, and histopathological examination. Patients were given therapy for benzathine penicillin G 2.4 million units singledose intramuscular and antiretroviral therapy. After given antibiotic and antiretroviral therapy, clinical conditions are improved and no manifestations of primary, secondary, nor tertiary syphilis. At the $3^{\text {rd }}$ month evaluation, there were four times the fold decrease in VDRL titers and become non-reactive in the $6^{\text {th }}$ month. Patients will continue to be followed up at $9^{\text {th }}, 12^{\text {th }}$ and $24^{\text {th }}$ months for VDRL titers. Patients are advised to be loyal to one partner and use a condom when having sex.

\section{REFERENCES}

Ahn, Jin Young et al. (2016). Incidence of Syphilis Seroconversion among HIV-Infected Persons in Asia: Results from the TREAT Asia HIV Observational Database. Journal of the International AIDS Society 19(1): 1-8.

Carlson, J. Andrew, Ganary Dabiri, Bernard Cribier, and Stewart Sell. (2011). The Immunopathobiology of Syphilis: The Manifestations and Course of Syphilis Are Determined by the Level of Felayed-Type Hypersensitivity. American Journal of Dermatopathol 33(5): 433-60.

Daili, Sjaiful Fahmi et al. (2013). Kementrian Kesehatan Republik Indonesia Direktorat Jenderal Pengendalian Penyakit dan Penyehatan Lingkungan Pedoman Tata Laksana Sifilis Untuk Pengendalian Sifilis Di Layanan Kesehatan Dasar. Jakarta: Kementrian Kesehatan Republik Indonesia Direktorat Jenderal Pengendalian Penyakit dan Penyehatan Lingkungan.

Frieden, Thomas R. et al. (2015). 64 Center for Disease Control and Prevention The Morbidity and Mortality Weekly Report (MMWR). Eds. William L. Roper et al. Washington: U.S. Department of Health and Human Services. http://www.cdc. gov/ 


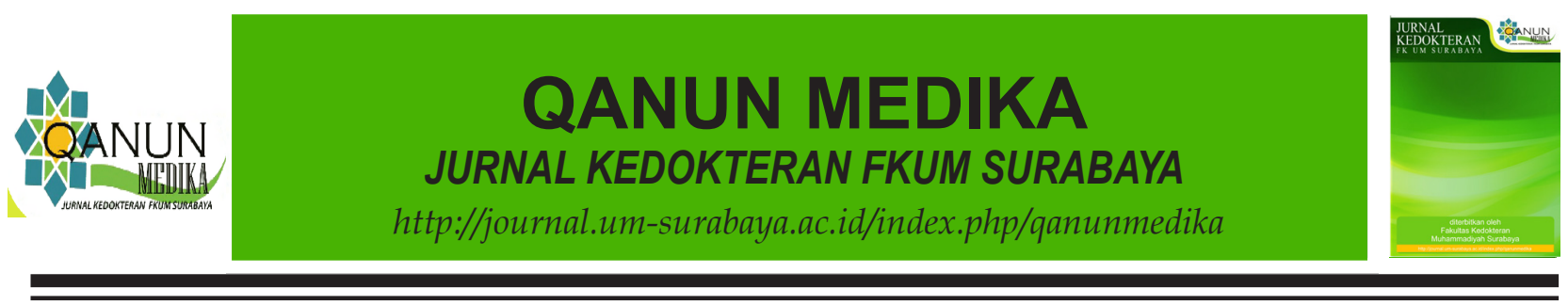

$\mathrm{mmwr} /$ preview/mmwrhtml/rr6403al.htm?s cid=rr6403a1_w.

Hutchinson, Catherine M. et al. (1994). Altered Clinical Presentation of Early Syphilis in Patients with Human Immunodeficiency Virus Infection. Annals of Internal Medicine 121(2): 94-99.

Jackson, Adrianna J., and Vera H. Price. (2013). How to Diagnose Hair Loss. Dermatologic Clinics 31(1): 21-28.

Karp, Galia, Francisc Schlaeffer, Alan Jotkowitz, and Klaris Riesenberg. (2009). Syphilis and HIV Co-Infection. European Journal of Internal Medicine 20(1): 9-13. http://dx.doi.org/10.1016/j. ejim.2008.04.002.

Lukehart, Sheila A. (2008). Biology of Treponemes. In Sexually Transmitted Diseases 4th Edition, eds. King K Holmes et al. New York: Mc-Graw-Hill, 647-59.

Pialoux, Gilles et al. (2008). Effect of HIV Infection on the Course of Syphilis. Aids Reviews 10: 85-92.

Pisani, Elizabeth et al. (2004). HIV, Syphilis Infection, and Sexual Practices among Transgenders, Male Sex Workers, and Other Men Who Have Sex with Men in Jakarta, Indonesia. Sexually Transmitted Infections 80(6): 536-40.
Rowawi, R, T. S. Djayakusumah, and P. A Achdiat. (2018). Sifilis Pada Pasien HIV/ AIDS. In Manifestasi Dan Tatalaksana Kelainan Kulit Dan Kelamin, eds. Afif Nurul Hidayati et al. Jakarta: Badan Penerbit FKUI, 19-50.

Solomon, Marc M., and Kenneth H. Mayer. (2015). Evolution of the Syphilis Epidemic among Men Who Have Sex with Men. Sexual Health 12(2): 96-102.

de Sousa, Isabel Cristina Valente Duarte. (2013). Simultaneous Primary and Secondary Syphilis Associated with Syphilitic Alopecia and Folliculitis in an HIV Positive Patient. Hair : Therapy \& Transplantation 03(01): 108-10.

Szetela, Bartosz, and Jacek Gasiorowski. (2016). Rapid Progression and Overlapping of Skin Eruptions in a Patient with Secondary and Tertiary Syphilis Co-Infected with HIV. AIDS Research and Human Retroviruses 32(9): 874-75.

UNAIDS. (2020). Country Factsheets INDONESIA 2018. https://www.unaids.org/ en/regionscountries/countries/indonesia (April 8, 2020). 